\title{
Article \\ Deinking of Screen-Printed Electrodes Printed on Invasive Plant-Based Paper
}

\author{
Urška Kavčič * (1), Igor Karlovits and Janja Zule \\ Pulp and Paper Institute, Bogišićeva 8, 1000 Ljubljana, Slovenia; igor.karlovits@icp-lj.si (I.K.); \\ janja.zule@icp-lj.si (J.Z.) \\ * Correspondence: urska.kavcic@icp-lj.si
}

Received: 21 January 2020; Accepted: 9 February 2020; Published: 12 February 2020

check for updates

\begin{abstract}
The deinking of paper-based printed electronics is a growing concern regarding the increase of printed electronics products. The benefits of using paper-based substrates instead of polymer or ceramic for the single-use printed electrodes can contribute to sustainability goals. The use of invasive plant species for making paper substrates for printed electronics is a unique opportunity to have several environmental benefits. In this study, the recycling issue of these products through the use of the deinking technique was evaluated. Screen-printed electrodes printed on an invasive plant-based paper and commercial cardboard were deinked, and their optical, morphological, and silver residues in paper and corresponding water extract were analyzed. The invasive plant-based paper had higher silver content in the recycled paper sheets, which influenced the optical and surface resistivity and residue ink particle number. On the other hand, the surface-treated cardboard had lower silver particle content after deinking, but higher silver concentrations in the water extract. The results indicate that ink-paper surface and ink-fibre interaction and adhesion is vital in the ink silver particles binding during the deinking process.
\end{abstract}

Keywords: deinking; printed electronics; screen-printed electrodes; paper electronics; invasive plant-based paper

\section{Introduction}

Printed electronics is a technology that emerges very fast and enables printing of functional materials onto different printing materials to produce several electronic devices, such as sensors, displays, RFID tags, and different electrodes which are used for various types of applications [1]. Screen-printed electrodes (SPEs) are useful tools for monitoring environmental parameters [2]. They are printed with three different printing inks in three layers (Figure 1b) and are used in various applications in wastewater evaluation, biochemistry, medicine, etc. [3].

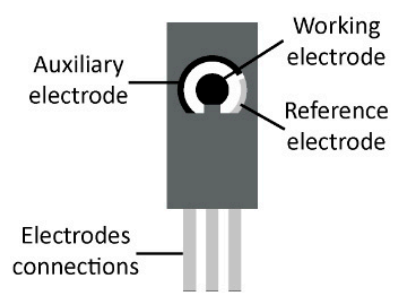

(a)

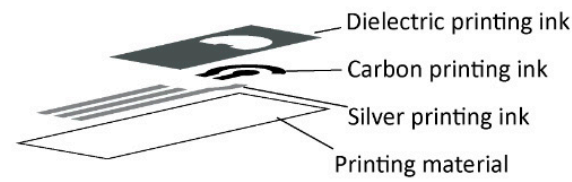

(b)

Figure 1. Screen-printed electrode with its parts (a) and the presentation of three different printing layers $(\mathbf{b})$. 
For the aforementioned purposes, mainly the modified [4-6] or non-modified commercially available SPEs printed on ceramics are used (DropSens, Metrohm Autolab, Gamry, etc.). An alternative to using commercially available SPEs is to screen print the SPEs on different, lighter, and biodegradable printing materials that are low-cost, such as paper. By using paper as the printing material, sustainable SPEs or other printed electronics can be made [7-12]. From the environmental sustainability point of view, printing on recyclable and biodegradable materials presents the must for all future developments. Not only the development of more green printing material should be taken into account, but the analysis of recyclability of printed electronics on paper products is also important for the evaluation of the lifecycle impact of the developed product. In the case of disposable printed electronics (such as SPEs), the lifecycle and end of service have to be taken into account primarily due to the nature of the used inks. For example, if these paper products end up in a waste stream with other paper-based products intended for recycling, additional consideration should be taken into account, i.e., the recycling/reuse strategies. Keskinen [13] discusses the end-life options for printed electronics, and there have been already done some researches about the recyclability of printed electronics on paper, such as RFID tags [14] and paper-based printed electronics $[15,16]$. They are all using different commercially available paper substrates mainly made from classical wood processing or recycling production processes. Recently, invasive alien plant species have been found to be a potential fibre source for paper-based materials, as many European cities are facing the invasion of alien plant species. Fibres which can be locally harvested and extracted from those plants can be used for the production of special paper substrates [17] and also can be used as a printing material for printed electronics. That way, we are moving towards a more circular economy, as there is a smaller environmental burden on the wood raw materials, and also the benefit of protecting local biosphere and plant species as an additional positive effect.

To our knowledge, there are just a few researches that evaluate the printing on invasive plant-based paper [18-20], and none of them deal with the deinking of SPEs printed on invasive plant-based paper. Deinking is the process for removing printing inks from fibres in order to improve optical characteristics of paper made out of deinked pulp [21]. The deinking process is performed in two phases, first being sample preparation and defibration with the addition of deinking chemicals such as sodium hydroxide, sodium silicate, hydrogen peroxide, and hydrophobic surfactant or collector, which is usually composed of long-chain fatty acid soaps. At this stage, fibres swell, and ink particles are detached from the surface due to the addition of a dispersant. In the second step, deinking takes place in the flotation cell where hydrophobic collector attaches air bubbles to ink particles, after which bubbles rise and are finally collected as foam on the surface [22]. For a flotation deinking process to be successful, the printing ink has to be hydrophobic and need to be in a certain particle size range to be appropriate for the flotation process. The rigidity and geometry of ink particles as well as the interaction between the ink and the printing material are also important [21]. The adhesion of the screen printing ink onto paper surfaces is mainly with absorption and penetration entanglement of ink components onto the paper structure. Due to the high ink film thickness, other properties like surface energy is less of importance for the cracking the adhesion between the ink and paper surface layer.

The purpose of the conducted research is to analyze the possibility of recycling/deinking of the printed SPEs directly (1) on the paper made out of invasive plant Japanese knotweed fibres, and for the comparison, (2) on the commercially available cardboard. The influence of used printing materials and silver conductive printing inks on deinking values was analyzed. The screen-printed SPEs were deinked according to modified INGEDE 11 method, and from the deinked pulp, handsheets were produced and analyzed. To fully evaluate the differences due to the used printing materials, several tests were conducted. The surface and optical properties were analyzed for ISO brightness. Printing ink particle residues were tested by image processing techniques, and also morphological analysis was made by scanning electron microscopy. Surface adhesion of the inks to the surface was also tested. The remaining silver content in the sheets was tested by means of measuring electrical resistance/resistivity of deinked paper samples, and chemical analysis of the silver content of handsheets 
and their corresponding water extracts was determined. This was important to map out the potential health threats due to the use of silver as a heavy metal component which can be released in the water-based mixing procedure of industry-based recycling and deinking in the waste paper streams.

\section{Materials and Methods}

\subsection{Printing}

For the experiment, SPEs with $4 \mathrm{~mm}$ working electrode (Figure 1a) were designed and printed onto two different printing materials: (1) JK-paper made out of Japanese knotweed fibres $\left(230 \mathrm{~g} / \mathrm{m}^{2}\right.$, Pulp and Paper Institute, Slovenia) and for the comparison, (2) ETB-commercially available Excellent Top Brown cardboard ( $250 \mathrm{~g} / \mathrm{m}^{2}$, MM Karton, Austria). The substrates were chosen due to their previous good properties regarding printability of such kind of printed structures. For the JK paper, $38 \%$ of alkaline delignified Japanese knotweed fibres, $31 \%$ of eucalyptus, and $31 \%$ of spruce virgin fibres were used. For the ETB cardboard, $95 \%$ of virgin hardwood fibres and $5 \%$ of surface coating were used, where the coating consisted from calcium carbonate mineral pigments, SB latex as binder, and other viscosity and shear thinning additives. The JK sample was not coated with surface coating but was sized where also calcium carbonate, AKD (Alkyl ketene dimer) as internal sizing agent and starch was used as binder. Printing in three layers (Figure 1b) was performed using semi-automatic screen printing machine GTO EVO 570 (GTO, Casalgrande RE, Italy) with the printing and curing conditions presented in Table 1.

Table 1. Printing and curing conditions.

\begin{tabular}{|c|c|c|c|c|}
\hline Part of SPE & Printing Ink Type & Printing Ink & $\begin{array}{l}\text { Screen Mesh } \\
\text { Count [lines/cm] }\end{array}$ & $\begin{array}{l}\text { Curing } \\
\text { Conditions }\end{array}$ \\
\hline $\begin{array}{c}\text { Contacts and } \\
\text { reference electrode }\end{array}$ & Silver printing ink & $\begin{array}{l}\text { CRSN 2442, SunTronic Silver } 280 \\
\text { (SunChemical, USA) }\end{array}$ & $120-31$ & $90 \mathrm{~s}$ at $90^{\circ} \mathrm{C}$ \\
\hline Working electrode & $\begin{array}{l}\text { Carbon printing } \\
\text { ink }\end{array}$ & $\begin{array}{l}\text { PE-C200 Carbon resistive ink } \\
\text { (Applied Ink Solutions, USA) }\end{array}$ & $77-55$ & $180 \mathrm{~s}$ at $120^{\circ} \mathrm{C}$ \\
\hline Insulation & $\begin{array}{l}\text { Dielectric printing } \\
\text { ink }\end{array}$ & $\begin{array}{l}\text { Grey dielectric paste D2070423P5 } \\
\text { (SunChemical, USA) }\end{array}$ & $90-48$ & $180 \mathrm{~s}$ at $120^{\circ} \mathrm{C}$ \\
\hline
\end{tabular}

\subsection{Printing Ink Adhesion}

For the determination of printing ink-printing material adhesion, a cross-cut test was performed on silver and carbon printing ink printed on both printing materials according to ISO 2409:2013 standard. For the test, the Byko-cut universal (BYK-Gardner GmbH, Germany) instrument was used. After cross-cutting the surface, the ISO classes were determined according to the grid area magnification.

\subsection{Deinking}

The evaluation of deinking efficiency was performed using the modified INGEDE Method 11.

\subsubsection{Sample Preparation}

Both samples were aged for $72 \mathrm{~h}$ at $60{ }^{\circ} \mathrm{C}$. Samples were then cut to small pieces from which $5 \%$ tap water suspension was prepared. The latter was mixed with deinking chemicals, e.g., $0.6 \% \mathrm{NaOH}$, $1.8 \% \mathrm{Na}_{2} \mathrm{SiO}_{3}, 0.7 \%$ of $\mathrm{H}_{2} \mathrm{O}_{2}$, and $3 \%$ of the collector, which is used in industrial deinking. All values were calculated on the dry weight of the sample.

\subsubsection{Pulping}

The suspension was defibrated at $45^{\circ} \mathrm{C}$ for $20 \mathrm{~min}$ in a laboratory defibrator after which it was kept for $60 \mathrm{~min}$ at the same temperature. The $\mathrm{pH}$ value was 9.9. A portion of $100 \mathrm{~g}$ was taken out, diluted, and filtered through a paper filter of low density. The residue on the filter was used for the 
determination of concentration, ISO brightness, and afterwards for ash content at $525^{\circ} \mathrm{C}$ according to TAPPI T211.

\subsubsection{Flotation}

The remaining sample was diluted to a concentration of $0.42 \%$ and transferred to the flotation cell with the constant flow of air bubbles, which lasted for $12 \mathrm{~min}$ at the temperature of $45^{\circ} \mathrm{C}$. The generated foam on the surface was removed, dried, and weighed. The deinked suspension was filtered through a paper filter for the determination of concentration, ISO brightness, and ash after which total yield and fibres yield were calculated.

\subsubsection{Handsheets}

Handsheets were prepared from undeinked pulp (UP) and deinked pulp (DP) according to ISO 5269-2:2004 using Rapid-Köthen sheet former. They were used for the determination of electrical resistance/resistivity and image analysis as well as for the determination of silver (Ag) content in deinked paper and in the corresponding water extract.

\subsection{ISO Brightness}

ISO brightness was determined on the original printing materials as well as on undeinked pulp (UP) and on deinked pulp (DP) according to ISO 2470-1:2016 standard using Elrepho $450 \times$ (Datacolor, Lawrenceville, New Jersey, USA) spectrophotometer, which used spherical measurement geometry, D65 illuminant, and measurement patch size of $6 \mathrm{~mm}$.

\subsection{Electrical Resistance/Resistivity}

The electrical surface and volume resistance/resistivity were measured on both printing materials after the deinking process. The measurement was performed on Agilent 4339B High-Resistance Meter by using the 16008B Resistivity Cell, which is used to measure insulation materials. The volume resistivity is measured across the material (MUT) by the unguarded and guarded electrodes, while on the other hand, the surface resistance is measured along the surface of the MUT. For the measurement, the $50 \mathrm{~mm}$ electrode with the potential of $500 \mathrm{~V}$ was used and charging time of $60 \mathrm{~s}$ and $10 \mathrm{~kg}$ of applied pressure. As the humidity and temperature can influence the measurements, the testing was done under controlled climatic conditions.

\subsection{Image Analysis}

To evaluate the surface properties and morphology of both deinked papers scanning electron microscopy was performed using a JSM-6060 LV (Jeol, Japan). The surfaces of both deinked papers were captured with a scanner (600 ppi) and the number of printing ink particles presented on the surface was analyzed using image analysis (ImageJ software ver $1.51 \mathrm{k}$, Public domain). The threshold of the grayscale image was set to values between 170 and 255, and binary images were analyzed. The printing ink particles were divided into six groups $\left(0.00-0.99 \mu \mathrm{m}^{2}, 1.00-1.99 \mu \mathrm{m}^{2}, 2.00-2.99 \mu \mathrm{m}^{2}\right.$, $3.00-3.99 \mu \mathrm{m}^{2}, 4.00-4.99 \mu^{2}$, and $>5.00 \mu \mathrm{m}^{2}$ ) and counted on the area of $100 \mathrm{~cm}^{2}$.

\subsection{Silver Content}

The silver content was determined in deinked fibre sheet and in the corresponding water extract, which was prepared according to SIST EN 645. $10 \mathrm{~g}$ of paper was cut to small pieces, mixed with $200 \mathrm{~mL}$ of deionized water, and left $24 \mathrm{~h}$ at room temperature with occasional shaking. The sample was filtered off and the filtrate (extract) was acidified with $\mathrm{H}_{2} \mathrm{SO}_{4}$ to $\mathrm{pH}<2$. The digestion of paper took place in the Milestone Ultrawave ECR digestor. $0.1 \mathrm{~g}$ of sample was weighed into a Teflon cell, to which a digestion mixture consisting of $5 \mathrm{~mL} \mathrm{HNO}_{3}, 1 \mathrm{~mL} \mathrm{H}_{2} \mathrm{O}_{2}$ and $0.1 \mathrm{~mL} \mathrm{HF}$ was added. The content was heated for $1 \mathrm{~h}$ at $200{ }^{\circ} \mathrm{C}$ after which it was cooled down to room temperature, quantitatively 
transferred to $25 \mathrm{~mL}$ volumetric flask and diluted with deionized water to the mark. The measurement of Ag concentration was conducted according to ISO 17294-2 on Agilent ICP MS 7700x instrument equipped with MassHunter Workstation software. Digested samples and water extracts were analyzed for total Ag content for which calibration curves were produced by plotting the signal as a function of concentration in the range between 0.5 and $50 \mathrm{ng} / \mathrm{mL}$ from stock standard Ag solution. Silver signal was monitored at ${ }^{107} \mathrm{Ag}$. Instrument settings were adjusted according to the producers' instructions.

\section{Results and Discussion}

\subsection{Printing}

The relative areas of the tested materials JK and ETB printed with each individual printing ink are presented in Table 2.

Table 2. Area of printing material printed with each of three printing inks.

\begin{tabular}{ccc}
\hline Printing Ink Type & Printed Area on JK [\%] & Printed Area on ETB [\%] \\
\hline Silver printing ink & 5.81 & 5.39 \\
Carbon printing ink & 1.87 & 1.74 \\
Dielectric printing ink & 15.17 & 14.09 \\
Total printed area & 22.85 & 21.22 \\
\hline
\end{tabular}

\subsection{Printing Ink Adhesion}

Printing ink adhesion to the printing material is one of the factors that can crucially influence the deinking process. As can be seen from Figure 2, it is evident that the adhesion of both (silver and carbon) printing inks to the ETB printing material is much worse in comparison to JK printing material. In the case of JK printing material, both printing inks reach ISO Class 2 (affected cross-cut area is from $5 \%$ to $15 \%$ ). On the other hand in the case of ETB printing material silver printing ink reach ISO Class 3 (affected cross-cut area from 15\% to 35\%), while carbon printing ink is even worse, reaching ISO Class 4 (affected cross-cut area from $35 \%$ to $65 \%$ ). 


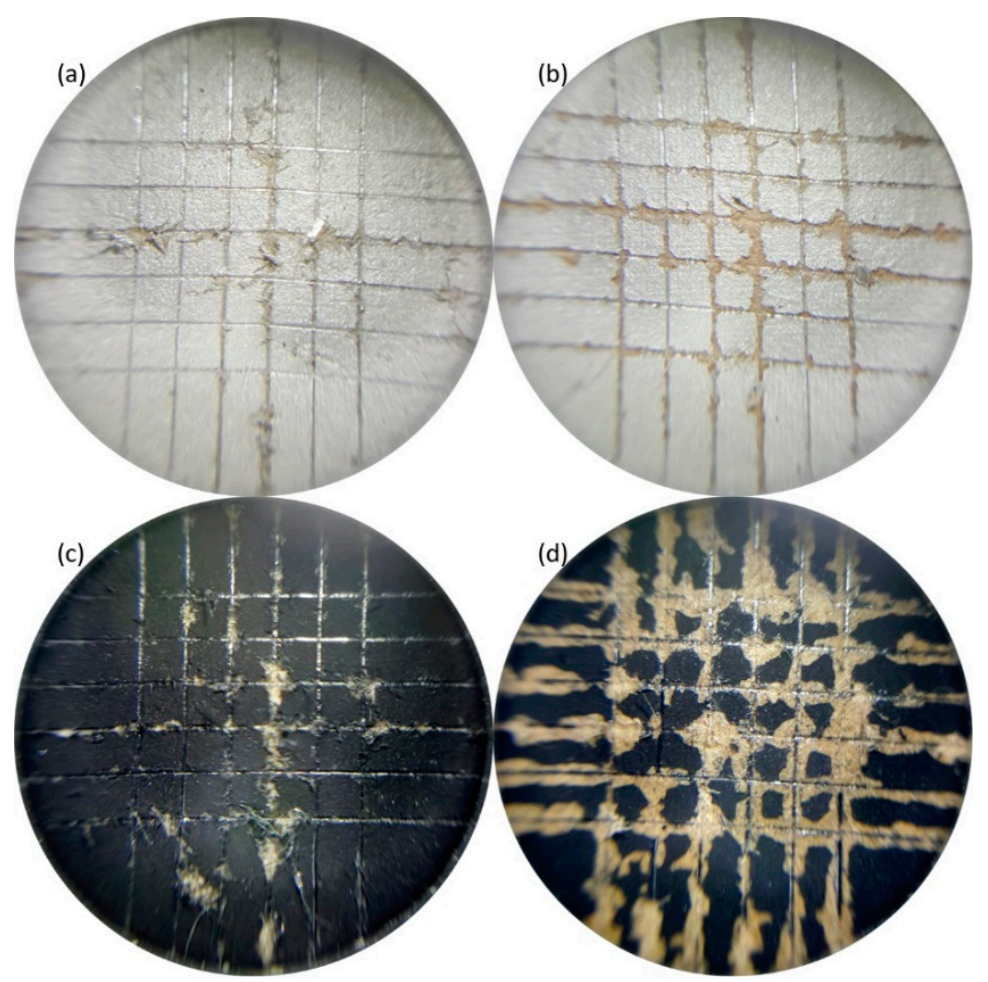

Figure 2. Analysis of printing ink adhesion with cross-cut test: (a) silver printing ink on JK, (b) silver printing ink on ETB, (c) carbon printing ink on JK and (d) carbon printing ink on ETB.

\subsection{Deinking}

Total yield and fibre yield for both materials resulting from the deinking experiment are presented in Table 3.

Table 3. Ash content of undeinked (UP) and deinked (DP) fibres and yields by deinking of JK and ETB sample.

\begin{tabular}{ccccc}
\hline Sample & Ash UP (\%) & Ash DP (\%) & Total Yield (\%) & Fibre Yield (\%) \\
\hline JK & 1.9 & 1.2 & 99.6 & 98.4 \\
ETB & 3.8 & 3.3 & 96.3 & 93.0 \\
\hline
\end{tabular}

ETB fibres contain a larger portion of ash which could be partly ascribed to the coated surface of the material. By deinking some coating is removed together with printing ink, so the value of this parameter decreases. The same holds for JK, only that ash originates solely from fibres that compose the sheet, as there was no surface treatment applied.

\subsection{ISO Brightness}

Optical properties of recycled paper essentially impact its quality and represent the ability of printing ink to be removed during the deinking process. The ISO brightness of printing material and handsheets produced from undeinked and deinked pulp is presented in Figure 3. It is evident that the deinking process affects ISO brightness in both cases, JK and ETB as the value of this parameter increases. ISO brightness is higher in the case of ETB material and further increases as a consequence of deinking. This may be explained by the fact that printing ink binds to the pigmented surface, while on the other hand, it binds directly on the fibres by JK sample, which is also evident from the adhesion test. 


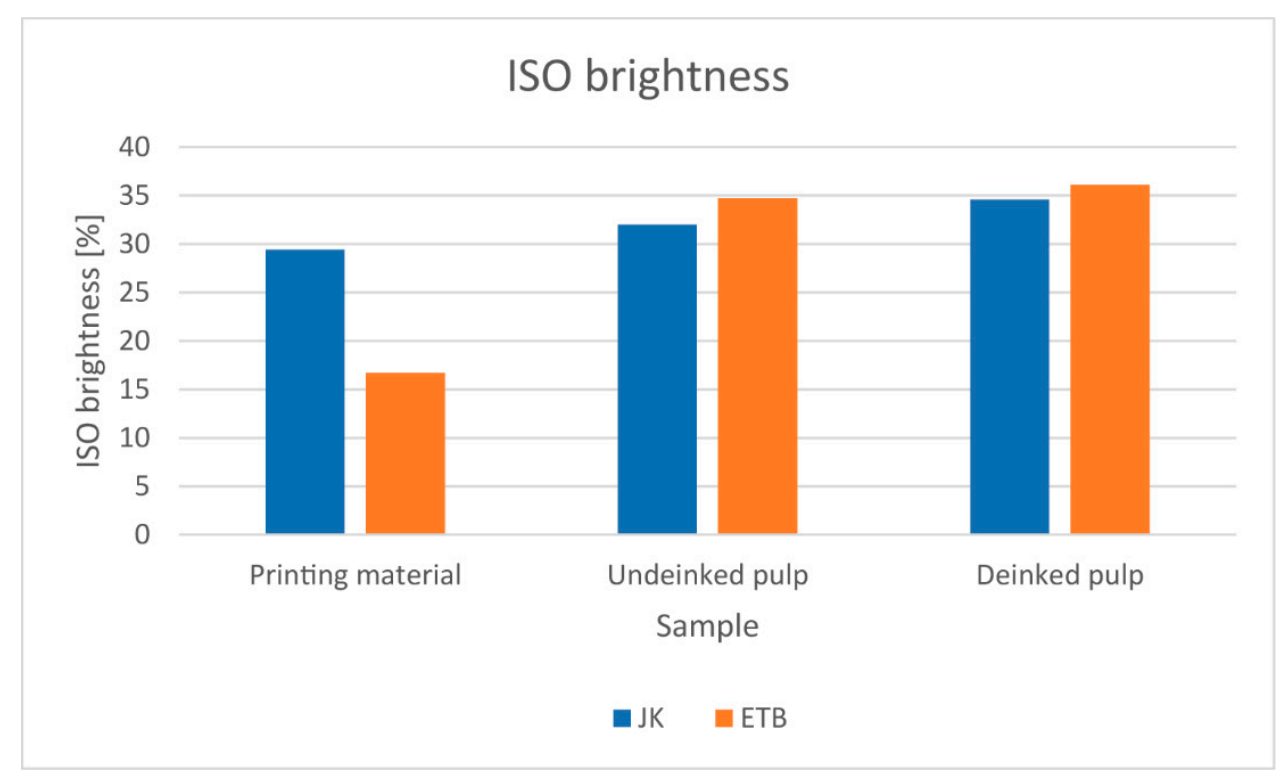

Figure 3. ISO brightness of both printing materials and laboratory sheets made from undeinked and deinked pulp.

\subsection{Electrical Resistance/Resistivity}

The surface resistance and especially the volume resistivity of paper were found to be strongly dependent on the electric field strength, the characteristics of this dependence being influenced by paper properties. As the papers had similar moisture content (JK 5.39\% and ETB 5.79\%) and the measurements were made in the standard condition, the differences in the surface resistance and volume resistivity are probably due to the silver content in the deinked handsheets. The surface resistance value of the JK sample is lower, which indicates that entrapped silver particles on the surface layer have lowered the resistivity as metal particles act as conductors (Figure 4).

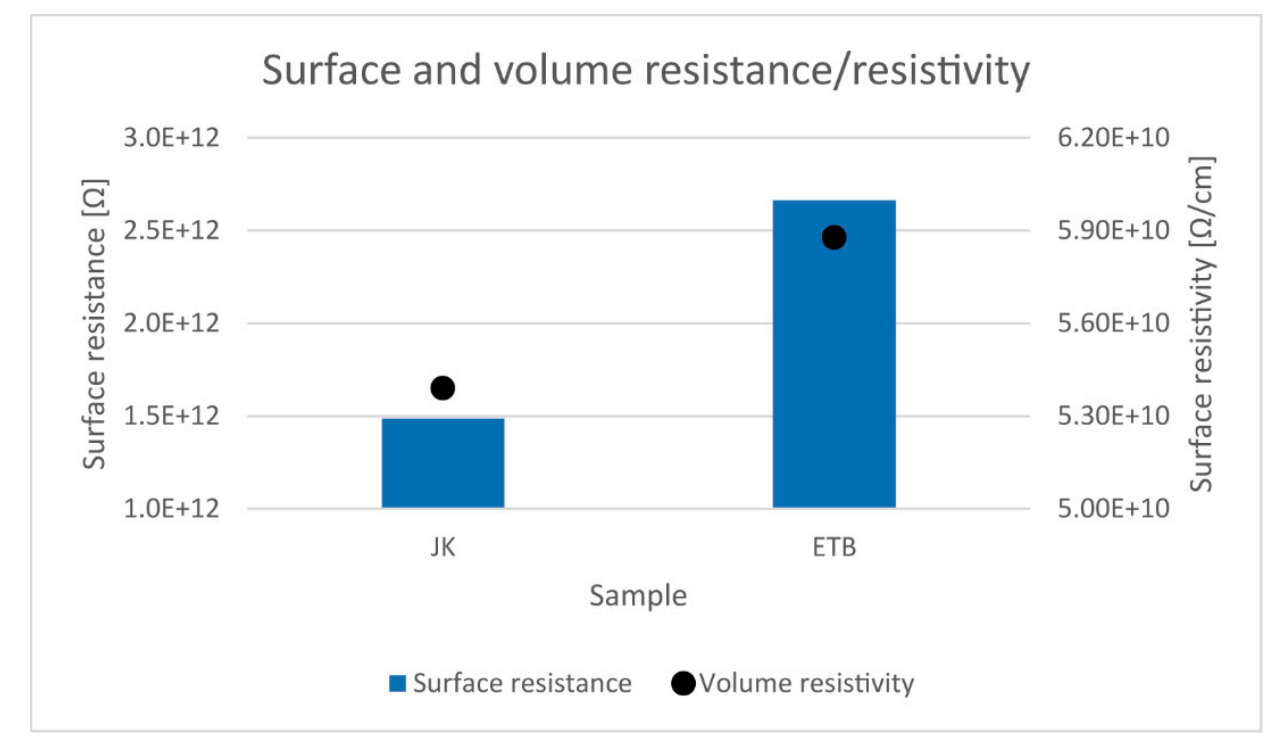

Figure 4. Surface and volume electrical resistance of JK and ETB sample after the deinking process.

\subsection{Image Analysis}

From the SEM images presented in Figure 5, it can be observed that the JK printing material is much rougher than ETB, which has additional surface treatment. This is why the printing ink on JK 
printing material penetrates more deeply into the paper (and attaches onto the fibres, and due to higher specific surface has more chance to make entanglement adhesion) while ETB printing ink remains on the material's surface.

(a)

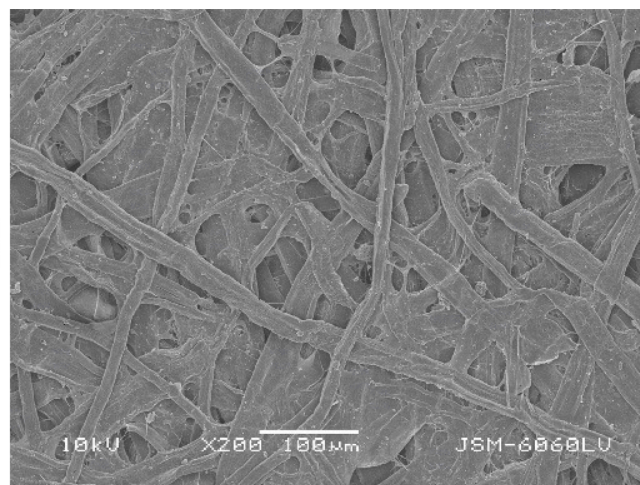

(c)

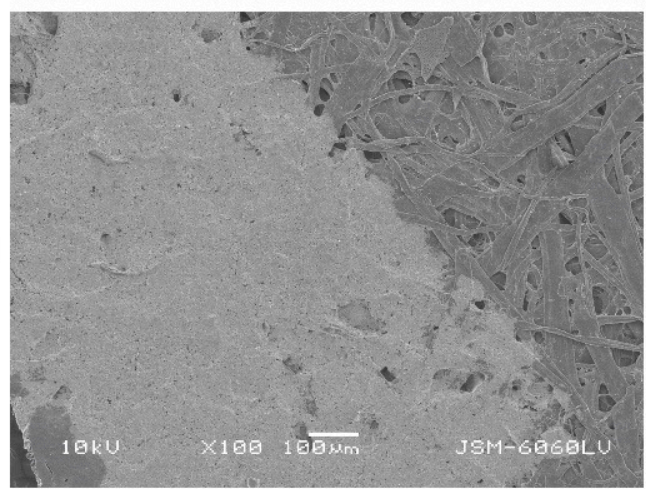

(e)
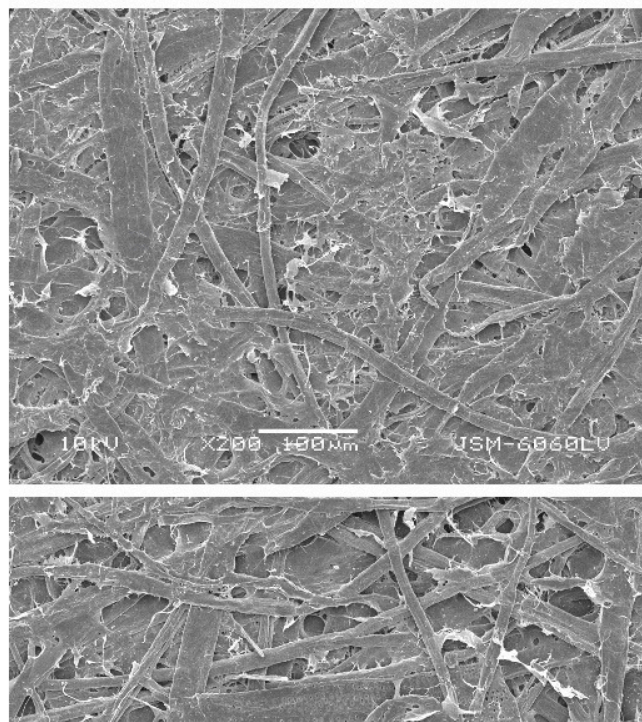

(g)

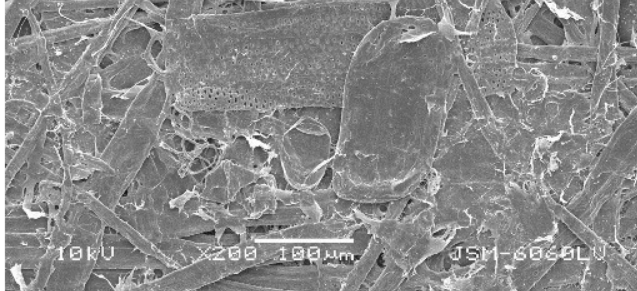

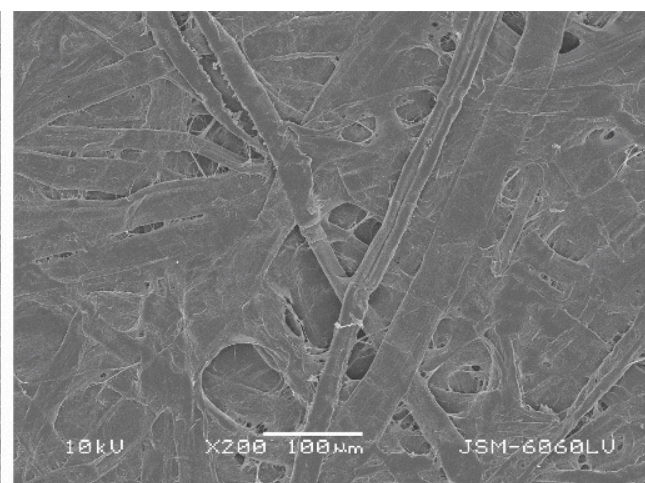

(b)

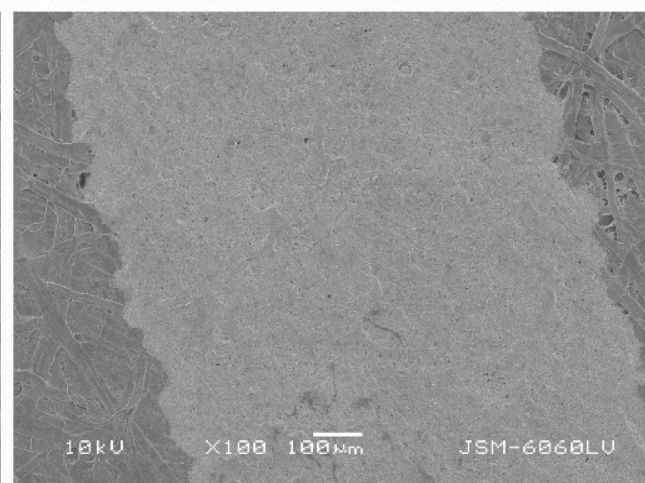

(d)

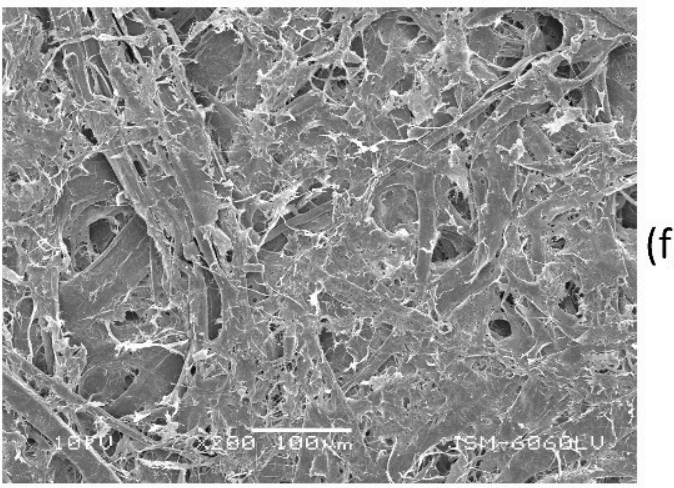

(f)

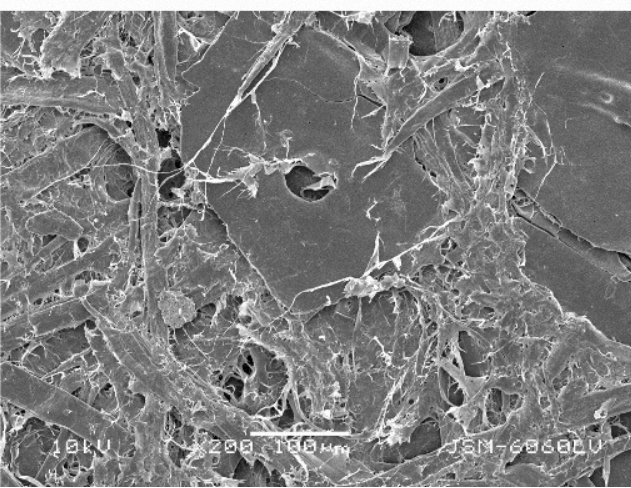

(h)

Figure 5. SEM images of printing material on (a) JK and (b) ETB; silver printing ink on (c) JK and (d) ETB printing material; (e) deinked JK paper; (f) deinked ETB paper, and printing ink on deinked (g) JK and (h) ETB. 
The surfaces of deinked samples are quite different, and the differences are visible to the naked eye. For the comparison, scanned surfaces and corresponding binary images which present the remained printing ink particles after the deinking process are presented in Figure 6.

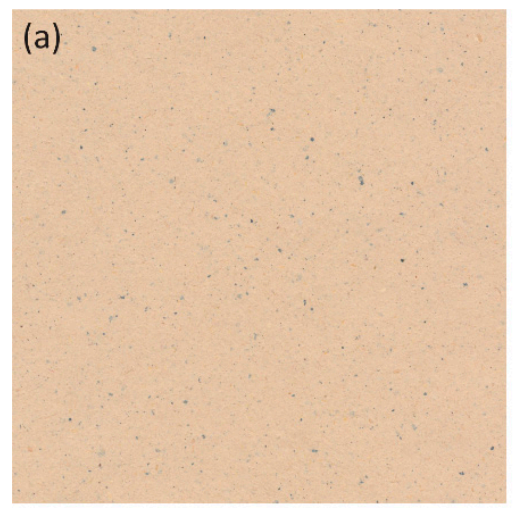

(c)

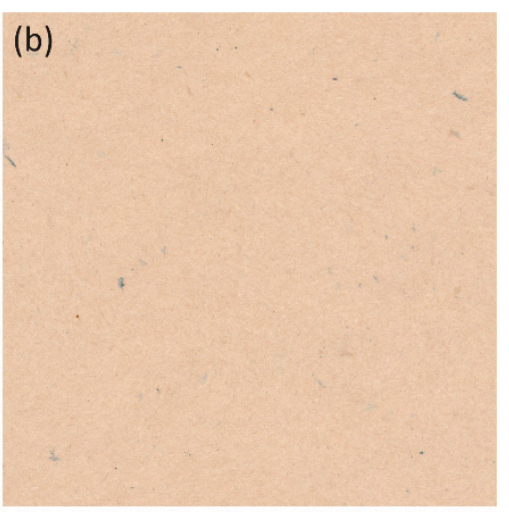

(d)

Figure 6. The surface of deinked (a) JK and (b) ETB sample; binary image of printing ink particles remained after the deinking process on (c) JK and (d) ETB sample.

Based on scanned images of deinked samples, the binary image of remained printing ink particles was determined, and finally, the particle counting procedure was performed. As it can be seen from Figure 6, there are much more particles presented on the surface of deinked JK sample than on the surface of the ETB sample. The total coverage of the area with remained (undeinked) printing ink regarding image analysis is $0.81 \%$ on JK sample and $0.12 \%$ on ETB sample. In both cases, the largest majority of particles are smaller than $1 \mu \mathrm{m}^{2}$, but there are also few larger than $100 \mu \mathrm{m}^{2}$. Nevertheless, the fact that all remained printing ink particles do not lay on the upper layer of the surface and are covered with some fibres but still visible should also be taken into account. Consequently, these particles do not have a contrast high enough to be detected when converting the image into a binary image and are not part of the results presented in Figure 7. 


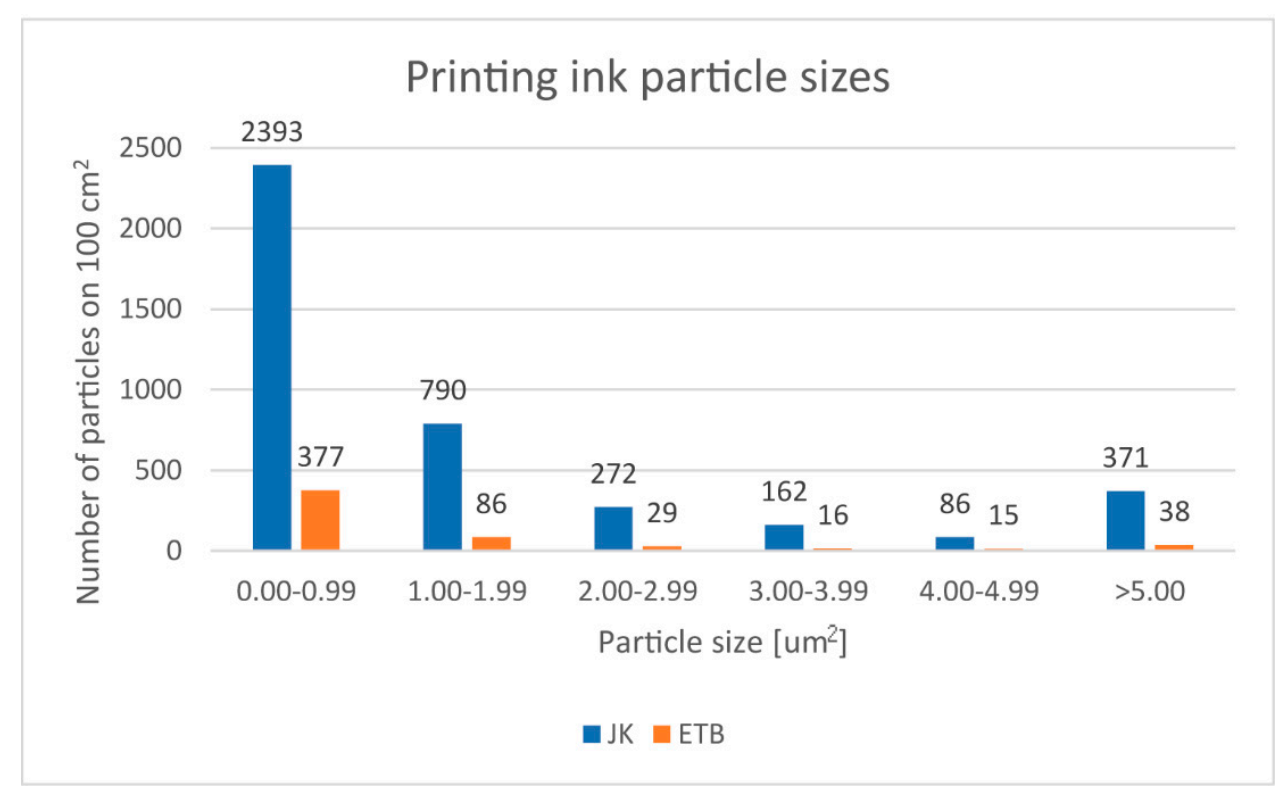

Figure 7. The number of printing ink particles presented on the surface of deinked samples considering particle sizes.

\subsection{Silver Content}

Silver content that remains in the paper after the deinking process (Figure 8) is quite different regardless of almost the same content of silver printing ink (Table 2) that was printed on samples used for deinking. The content of silver, which is irreversibly bound to fibres, is much higher in the case of JK. However, only a small portion of it is leached out. By ETB, it is just the other way around as a much smaller portion of silver remains bound to deinked pulp, so the extent of leaching is consequently much bigger. This could be explained by the fact that $\mathrm{Ag}$ in the form of $\mathrm{Ag}^{+}$ions binds more strongly to the fibres than to the coating. Ag is a heavy metal and its accumulation in water circuits may be problematic because it may impact living organisms by entering the food chain. $\mathrm{Ag}^{+}$may combine with anions, usually present in water, as for example, nitrates to form toxic $\mathrm{AgNO}_{3}$. Due to the fact that modern deinking facilities recirculate a significant part of their technological water, it is highly probable that $\mathrm{Ag}$ starts to accumulate if released from paper substrates. Ag as well as other heavy metals can be efficiently removed from water by membrane filtration, ion exchange, adsorption, and other techniques, however this additional step makes the whole production process more complicated and expensive. For this reason, its firm interaction with fibres is desirable from the viewpoint of recycling as long as it does not essentially affect optical properties and thus the quality of deinked fibres. 


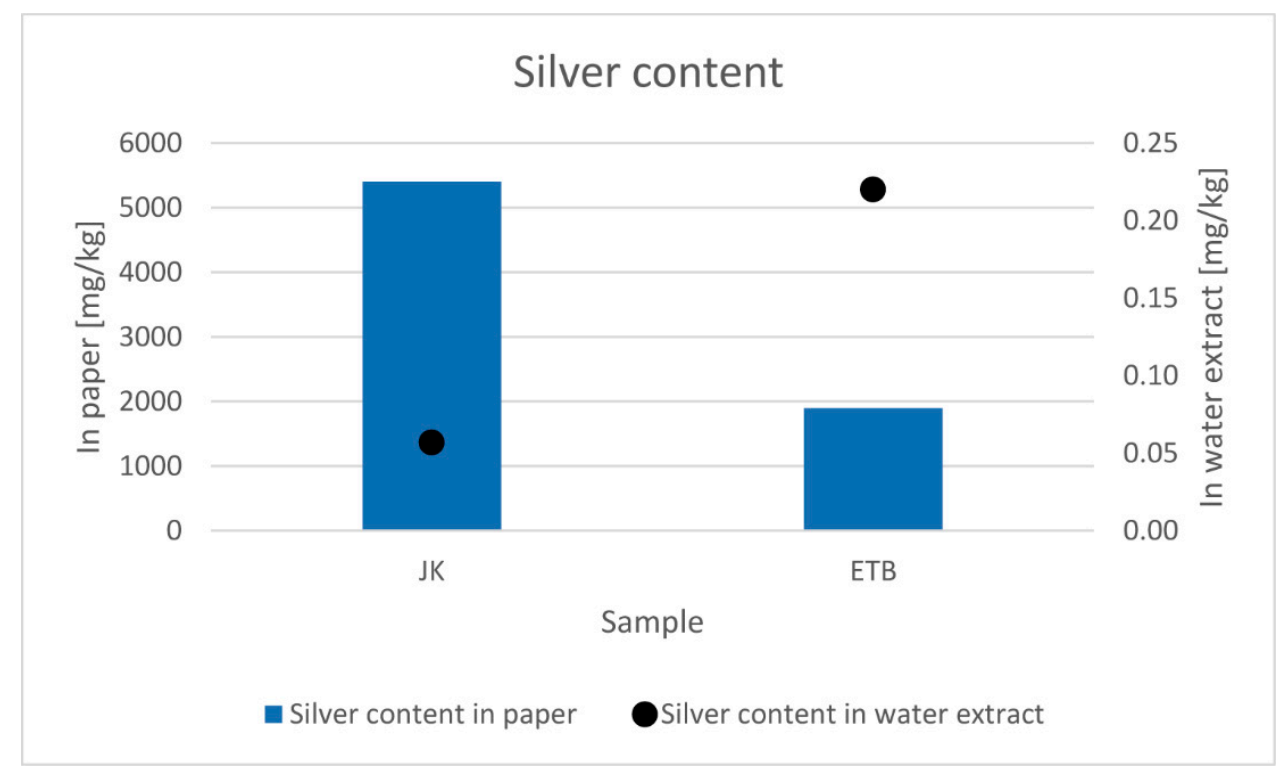

Figure 8. Silver content in the laboratory sheets after deinking process and in water extract.

\section{Conclusions}

The presented research has shown that paper containing printed electronics can be deinked. However, the efficiency depends on the nature of the substrate as well as printing ink. In addition, possible accumulation of silver particles (heavy metal) in water circuits during deinking has to be seriously considered in order to prevent negative environmental impacts of the process, as not all paper products are equally appropriate for recycling. Blayo et al. [15] conclude that the presence of fillers on the paper surface and in paper bulk affects the extraction of $\mathrm{Ag}$ from the fibrous matrix. There are few factors that can cause that, including the poor detachment of the ink from the paper coating, the difficulty to drag the particles in the hyper washing filtrate, or the complexity to separate fillers from silver by centrifugation. While in our case both samples were deinked by the same procedure and printed with the same printing ink, it is expected that the main reason for the differences in the deinking process observed is dependent on ink-printing material adhesion. As screen printing was used with hot air drying, the governing mechanism was by solvent evaporation and penetration. Due to the differences in porosity and surface roughness, the solvents (propylene/glycol ethers) penetrated and wetted the JK sample surface more. This deeper and more thorough laying of the printing ink resin on the fiber structure enhances the intertangling of the resin polymer and coating/fiber structure, and this improves the adhesion. From the results presented, it is clearly seen that the deinking process was more efficient with SPE printed on ETB printing material. In that case, the achieved ISO brightness was higher than with JK sample, much more ink particles were removed during the deinking process, and the content of silver present in deinked paper is lower than in JK sample, which can be the result of poor adhesion to the printing material. Contrary to silver content in paper, the silver content in water extract is much higher with ETB sample than with JK sample, which could be explained with lower adhesion between printing ink and board surface in the case of ETB sample than in the case of JK sample, which does not have any surface treatment (but has internal sizing with similar pigment structure to achieve comparable printability parameters with coated samples). Due to differences in pore diameter and open volume, this consequently results in that the printing ink bonds with entanglements directly to the fibres.

Author Contributions: Conceptualization, U.K. and I.K.; methodology, U.K. and I.K.; validation, U.K. and I.K. and J.Z.; investigation, U.K. and I.K. and J.Z.; writing-original draft preparation, U.K. and I.K.; writing-review and editing, U.K. and I.K. and J.Z.; visualization, U.K. All authors have read and agreed to the published version of the manuscript. 
Funding: This research was funded by Slovenian Research Agency, grant number J2-8182.

Acknowledgments: Slovenian Research Agency is gratefully acknowledged for funding via J2-8182.

Conflicts of Interest: The authors declare no conflict of interest.

\section{References}

1. Gonzalez-Macia, L.; Killard, A.J. 4-Screen printing and other scalable point of care (POC) biosensor processing technologies. In Medical Biosensors for Point of Care (POC) Applications; Narayan, R.J., Ed.; Woodhead Publishing: Cambridge, UK, 2017; pp. 69-98.

2. Hayat, A.; Marty, J.L. Disposable Screen Printed Electrochemical Sensors: Tools for Environmental Monitoring. Sensors 2014, 14, 10432-10453. [CrossRef] [PubMed]

3. Zhao, C.; Thuo, M.M.; Liu, X. A microfluidic paper-based electrochemical biosensor array for multiplexed detection of metabolic biomarkers. Sci. Technol. Adv. Mater. 2013, 14, 054402-054412. [CrossRef] [PubMed]

4. Gusmão, R.; López-Puente, V.; Yate, L.; Pastoriza-Santos, I.; Pérez-Juste, J.; González-Romero, E. Screen-printed carbon electrodes doped with $\mathrm{TiO} 2-\mathrm{Au}$ nanocomposites with improved electrocatalytic performance. Mater. Today Commun. 2017, 11, 11-17. [CrossRef]

5. López-López, L.; Miranda-Castro, R.; de-los-Santos-Álvarez, N.; Miranda-Ordieres, A.J.; Lobo-Castañón, M.J. Disposable electrochemical aptasensor for gluten determination in food. Sens. Actuators B Chem. 2017, 241, 522-527. [CrossRef]

6. Amouzadeh Tabrizi, M.; Shamsipur, M.; Saber, R.; Sarkar, S.; Besharati, M. An electrochemical aptamer-based assay for femtomolar determination of insulin using a screen printed electrode modified with mesoporous carbon and 1,3,6,8-pyrenetetrasulfonate. Microchimica Acta 2017, 185, 59. [CrossRef] [PubMed]

7. Määttänen, A.; Vanamo, U.; Ihalainen, P.; Pulkkinen, P.; Tenhu, H.; Bobacka, J.; Peltonen, J. A low-cost paper-based inkjet-printed platform for electrochemical analyses. Sens. Actuators B Chem. 2013, 177, $153-162$. [CrossRef]

8. Cinti, S.; Fiore, L.; Massoud, R.; Cortese, C.; Moscone, D.; Palleschi, G.; Arduini, F. Low-cost and reagent-free paper-based device to detect chloride ions in serum and sweat. Talanta 2018, 179, 186-192. [CrossRef] [PubMed]

9. Desmet, C.; Marquette, C.A.; Blum, L.J.; Doumèche, B. Paper electrodes for bioelectrochemistry: Biosensors and biofuel cells. Biosens. Bioelectron. 2016, 76, 145-163. [CrossRef] [PubMed]

10. Fletcher, S. Screen-Printed Carbon Electrodes. In Electrochemistry of Carbon Electrodes; Alkire, R.C., Bartlett, P.N., Lipkowski, J., Eds.; Wiley-VCH: Weinheim, Germany, 2015; pp. 425-444.

11. Li, M.; Li, Y.-T.; Li, D.-W.; Long, Y.-T. Recent developments and applications of screen-printed electrodes in environmental assays-A review. Analytica Chimica Acta 2012, 734, 31-44. [CrossRef] [PubMed]

12. Kavčič, U.; Pavlovič, L.; Pivar, M.; Đokić, M.; Batagelj, B.; Muck, T. Printed electronics on recycled paper and cardboards = Tiskana elektronika na recikliranem papirju in kartonu. Inf. MIDEM 2013, 43, 50-57.

13. Keskinen, M. 16-End-of-life options for printed electronics. In Waste Electrical and Electronic Equipment (WEEE) Handbook; Goodship, V., Stevels, A., Eds.; Woodhead Publishing: Cambridge, UK, 2012; pp. 352-364.

14. Gregor-Svetec, D.; Blaznik, B.; Pivar, M.; Bolanča-Mirković, I. Recyclability of printed RFID tags. In Proceedings of the ActInPack Conferences, Vienna, Austria, 20-22 November 2018; p. 145.

15. Blayo, A.; Marlin, N.; Chretien, C. About deinking of paper-based printed electronics. In Proceedings of the Iarigai Conference, Warsaw, Poland, 3-7 October 2018; pp. 157-164.

16. Aliaga, C.; Zhang, H.; Dobon, A.; Hortal, M.; Beneventi, D. The influence of printed electronics on the recyclability of paper: A case study for smart envelopes in courier and postal services. Waste Manag. 2015, 38, 41. [CrossRef] [PubMed]

17. Kapun, T.; Zule, J.; Šinkovec, A. Invasive alien plants - a burden for the environment or new opportunity for papermaking? In Proceedings of the IWBLCM 2019 Conference, Córdoba, Spain, 4-7 June 2019; pp. 131-135.

18. Lavrič, G.; Pleša, T.; Mendizza, A.; Ropret, M.; Karlovits, I.; Gregor-Svetec, D. Printability characteristics of paper made from a Japanese knotweed. In Proceedings of the 9th International Symposium on Graphic Engineering and Design, Novi Sad, Serbia, 8-10 November 2018; pp. 99-102.

19. Kavčič, U.; Karlovits, I. Invasive plant-based paper as a substrate for electroconductive printing inks. In Proceedings of the Advances in Printing and Media Technology, Darmstadt, Germany, 15-18 September 2019; pp. 165-170. 
20. Kavčič, U.; Karlovits, I. The Influence of Process Parameters of Disposable Invasive Plant Paper Screen-Printed Electrochemical Electrodes. Nord. Pulp Paper Res. J. 2020. in print.

21. HÖke, U.; Schabel, S. Recycled Fiber and Deinking; Paperi ja Puu Oy: Helsinki, Finland, 2010.

22. Fricker, A. Novel solutions to new problems in paper deinking. Pigment Resin Technol. 2007, 36, 141-152. [CrossRef] 